\section{$\underset{\substack{\text { hommes } \\ \text { \& migrations }}}{ }$}

\section{Hommes \& migrations}

Revue française de référence sur les dynamiques

migratoires

$1306 \mid 2014$

Ecriture et migration

\title{
Julien Delmaire, Georgia
}

Paris, Grasset, 2013, 256 pages, $17 €$.

\section{Michaël Ferrier}

\section{OpenEdition \\ 1 Journals}

\section{Édition électronique}

URL : http://journals.openedition.org/hommesmigrations/2824

DOI : 10.4000/hommesmigrations.2824

ISSN : 2262-3353

\section{Éditeur}

Musée national de l'histoire de l'immigration

\section{Édition imprimée}

Date de publication : 1 avril 2014

Pagination : 117-118

ISBN : 978-2-919040-27-8

ISSN : $1142-852 X$

\section{Référence électronique}

Michaël Ferrier, « Julien Delmaire, Georgia », Hommes \& migrations [En ligne], 1306 | 2014, mis en ligne le 06 août 2014, consulté le 22 septembre 2020. URL : http://journals.openedition.org/

hommesmigrations/2824; DOI : https://doi.org/10.4000/hommesmigrations.2824

Ce document a été généré automatiquement le 22 septembre 2020.

Tous droits réservés 


\section{Julien Delmaire, Georgia}

Paris, Grasset, 2013, 256 pages, $17 €$.

\section{Michaël Ferrier}

\section{RÉFÉRENCE}

Julien Delmaire, Georgia,

Paris, Grasset 2013, 256 pages, $17 €$.

\section{NOTE DE L'ÉDITEUR}

Sélection 2014 de la $5^{\mathrm{e}}$ édition du prix de la Porte Dorée.

1 Étrange roman, souvent émouvant, parfois flamboyant, toujours attachant. L'intrigue est simple : la rencontre de Venance, exilé du Sénégal en France, dont la vie quotidienne est "une embuscade permanente", traqué par la police et esclavagisé par les petits boulots, et Georgia, jeune artiste peintre révoltée contre la société et prise au piège de la drogue. Présenté ainsi, ce pourrait n'être qu'une chronique sociale comme une autre dans la France d'aujourd'hui. Mais pas du tout.

2 Ce qui frappe en tout premier lieu, c'est la qualité de l'écriture. Les notations sont précises, les portraits appuyés, les descriptions, tour à tour sèches ou poétiques, sonnent juste, qu'il s'agisse des personnages principaux (la mère avec sa "sollicitude de cadenas" - magnifique expression -, le jeune frère mort noyé, "fantôme roué de sel"), des personnages secondaires (le vieux Souleymane, Français autant que Sénégalais; le dealer Samba, très loin des clichés), ou encore d'une simple forme qui passe, comme ce vieillard avec la "peau aux nuances de pneus usés", "des gencives violettes et nues", qui disparaît dans un mausolée "avec la lenteur du sel". Delmaire soigne chaque page de son récit avec le soin d'un orfèvre.

3 Car l'essentiel est là : Delmaire a un style, un rythme, une musique. Cette phrase par exemple, quand le clandestin Venance est embarqué par les policiers. Lancée par son 
monosyllabe initial, elle se déverse ensuite entre les alexandrins et les métaphores, et cascade autant de grâce que de fougue : "Cri ! Les marais salants que le vent d'ouest exalte, les bêtes qui s'abîment dans la boue des mangroves, les kalachnikovs de seconde main vendues parmi les arachides, la malaria rampante dans les dédales de l'aube : ce cri résumait tout." On pense à Césaire - et il n'est pas immérité de dire que Delmaire ne déroge pas à son glorieux aîné.

Par sa construction aussi, Georgia soulève l'admiration : il y a de l'audace et un allant admirable, mais aussi un délicat savoir-faire dans ce premier roman où l'un des deux personnages principaux meurt au bout d'une trentaine de pages à peine ! À ce moment, on pense que le livre va s'enliser et peiner à trouver un autre souffle. Il n'en est rien : avec une sûreté et un métier étonnants pour un premier livre, la suite ne faiblit pas, exploitant toutes les coulisses de la remémoration, du souvenir d'enfance puis de la rencontre, selon un assemblage en cinq parties, à la fois astucieux et efficace, qui fait penser à un montage cinématographique. Si le texte prend parfois des allures de cri, il est évident qu'il est travaillé avec un admirable mélange de passion et de minutie.

$5 \quad$ C'est qu'une grande culture, discrète mais sensible, traverse aussi ces pages : y passent des accents de Jean Genet (notamment dans la première partie, qui rappelle parfois son poème "Le condamné à mort"), des échos surréalistes (la "Georgia" de Soupault, la Nadja de Breton), des souvenirs de Tchicaya U Tam'si... Roman nourri de références poétiques, mais aussi roman se servant de toutes les possibilités du roman (à la fois chronique sociale et description poétique, analyse psychologique et critique politique), Georgia se constitue ainsi, non pas comme "une hésitation prolongée entre le son et le sens" (comme le disait joliment Paul Valéry du poème), mais par leur alliage subtil, leur alliance réussie.

Enfin, qui ne voit la portée de ce livre pour notre temps? En nous parlant d'un exilé, Delmaire nous parle de nous et, avec une ironie grinçante, des drôles de temps que nous vivons aujourd'hui : "En ces temps héroïques, la France redoutait les morsures du devenir. (...) Les blagues les plus visqueuses qui d'habitude rampaient sur le zinc des comptoirs se voyaient prisées dans les ministères; les discours étaient de défiance et d'exhortation, et toujours le courage consistait à plaquer au sol des hommes à bout de souffle."

7 On pourra être agacé, en de rares endroits, par un excès de préciosité lyrique, ou épuisé par l'énergie que demande ce livre un peu fou qui semble rouler à tombeau ouvert vers sa fin catastrophique. Mais ce premier roman à la fois joyeux et cruel, qui siffle comme une balle et touche comme une flèche, est un livre palpitant, qui signe la naissance d'un superbe écrivain. 